Revista do Programa de Pós-graduação Interdisciplinar em Estudos do Lazer - UFMG

\title{
POR UMA ABORDAGEM DO LAZER LÍQUIDO
}

Recebido em: 06/02/2020

Aprovado em: 29/05/2020

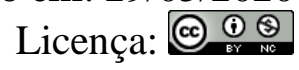

Luiz Fernando Roscoche

Universidade Federal do Pará (UFPA) - Campus de Bragança

Bragança - PA - Brasil

RESUMO: O presente trabalho tem como objetivo realizar uma revisão teórica da perspectiva da abordagem liquida do lazer. Para discutirmos o conceito de um lazer líquido, temos que tomar como referência as ideias de modernidade liquida cunhada pelo pensador polonês Zygmunt Bauman. Para adentrarmos a discussão do lazer líquido, nos referenciamos nas obras pioneiras dessa discussão, o pesquisador inglês, Tony Blackshaw. Partimos da premissa de que as abordagens tradicionais de discussão do lazer são suficientes dada a complexidade e multidimensionalidade dos fenômenos do lazer atualmente. $\mathrm{Na}$ contemporaneidade, num mundo de modernidade liquida os problemas não conseguem mais ser resolvidos com as fórmulas do mundo moderno sólido. A ideia de modernidade como um todo coerente e ordenado se desfaz. O mundo se tornou diversificado e múltiplo como nunca antes, um mundo no plural onde existem diferentes possibilidades existenciais.

PALAVRAS-CHAVE: Atividades de Lazer. Lazer Líquido. Modernidade Líquida.

\section{FOR A LEISURE LIQUID APPROACH}

ABSTRACT: The present work aims to carry out a theoretical review of the perspective of the liquid leisure approach. To discuss the concept of a liquid leisure, we have to take as a reference the ideas of liquid modernity coined by the polish thinker, Zygmunt Bauman. In order to enter the discussion of liquid leisure, we refer to the pioneering works of that discussion, the english researcher, Tony Blackshaw. We start from the premise that traditional approaches to the discussion of leisure are sufficient given the complexity and multidimensionality of leisure phenomena today. Nowadays, in a world of liquid modernity, problems can no longer be solved with the formulas of a solid modern world. The idea of modernity as a coherent and orderly whole falls apart. The world has become diverse and multiple as never before, a plural world where different existential possibilities exist.

KEYWORDS: Leisure Activities. Leisure Liquid. Liquid Modernity. 


\section{Introdução}

A nossa opção conceitual por uma conceituação de lazer, se baseia na ideia de que existem limitações teóricas ao conceber o lazer atrelado ao modelo de sociedades industriais, ou mesmo ao sistema capitalista, ou ainda considerado em uma dicotomia entre trabalho versus lazer. Preferimos mais do que definir atividades ou locais de lazer de maneira euclidiana, considerar que o lazer é a busca de satisfação, realização ou prazer, ainda que esta não se consume, de acordo com os interesses dos sujeitos. Ou segundo Ferreira (2010, p. 43) as atividades voltadas ao lazer procuram proporcionar uma excitação agradável ou um estímulo das emoções, através de escolhas e vontades individuais. O lazer seria, portanto, uma combinação de tempo e de atitude, que através da ação dos sujeitos o torna único. Dessa forma consideramos que conceituarmos o lazer segundo do uma perspectiva mais fluída (ou liquida para empregar o termo de Bauman (2001), coaduna com as atuais demandas de estudos de diferentes formas, seja pelo fato de que a conceituação contemporânea de lazer não se enquadraria no atual contexto social dadas as limitações teóricas existentes.

Aqui consideramos que não só o lazer pode ser considerado pela perspectiva da modernidade liquida de Bauman (2001), como também teria suas forças de tensão, no objeto de estudo em questão, primeiro a sociedade e a modernidade liquida que permeia toda a sociedade e por outro, certos redutos e instituições que resistem as mudanças dessa modernidade liquida, prometendo uma retropia (BAUMAN, 2017), ou seja, a tentativa de preservação de valores e formas de viver de tempos anteriores.

Quando nos referimos ao lazer visto pelas lentes da modernidade liquida de Bauman, estamos no pautando no trabalho pioneiro do pesquisador inglês, Tony Blackshaw, que busca através das lentes das teorias de Bauman, lançar luz sobre a reflexões em relação ao lazer. Antes de adentrar ao universo teórico da adaptação da teoria 
da modernidade liquida ao lazer, torna-se necessário contextualizar a obra e do sociólogo polonês Zygmunt Bauman, a partir das lentes de autores como Rojek e Blackshaw.

\section{Lazer Líquido na Perspectiva de Tony Blackshaw}

Muitas das conceituações e definições de lazer nos parecem defasadas no tempo, ou necessitando de uma nova atualização e contextualização. O mundo moderno e sólido e de certezas dá lugar cada vez mais a um mundo mais incerto, instável, ou líquido na metáfora de Bauman. Temos um novo tipo de sociedade que pode ser pensada na modernidade líquida ou também pós-moderna (ROJEK, 1995), onde tudo está em permanente mudança. O desafio atual, é ir além das dicotomias na análise do lazer, como a do trabalho e do lazer, entre o consumismo e a busca por autenticidade, ou aspectos positivos e negativos do lazer. O lazer significaria nas palavras de Blackshaw (2017a), um apelo ao desconhecido, a liberdade e todas as possibilidades de uma atividade pautada pela paixão, prazer e propósito, onde o lazer é sujeito de nossa devoção. Devoção aqui não entendida em seu aspecto sacro, mas sim na dedicação a essa atividade, buscando com isso o que o autor chama da arte de viver (onde o sujeito se torna protagonista de uma histórica escrita por ele mesmo). O lazer então é visto como uma fonte de significado para a vida, uma forma de imaginar e pôr em ação outro tipo de vida. Nessa leitura os indivíduos são considerados como seres atuantes na realidade e com potencial de transformação, não sendo vistos como meras vítimas determinísticas da sociedade.

Também se torna valido salientar que os estudos de lazer passaram pelo que Blackshaw(2017a), chama de crise do lazer, ou seja, uma crise silenciosa e profunda, que se abateu inclusive nas universidades, provocando declínio nos estudos do lazer. A crise é entendida aqui num primeiro momento como uma crise de legitimação que se reflete na dilapidação das bases explicativas e teóricas. Dessa forma, pode-se dizer que se tem uma 
crise de autoridade que "consiste precisamente no fato de que o velho está morrendo e o novo não pode nascer", ou o velho não consegue mais explicar a realidade frente aos novos processos.

Dito isso, consideramos que na contemporaneidade, num mundo de modernidade liquida os problemas não conseguem mais ser resolvidos com as fórmulas do mundo moderno sólido. A ideia de modernidade como um todo coerente e ordenado se desfaz. O mundo se tornou diversificado e múltiplo como nunca antes, um mundo no plural onde existem diferentes possibilidades existenciais. É nesse sentido que teóricos como Roberts, (1978, 1981) e Clarke e Critcher (1985), levantam a problemática dessa multidimensionalidade dos fenômenos do lazer. Outro salto qualitativo na abordagem do lazer é construído por Chris Rojek em suas obras Capitalism and Leisure Theory (1985), Decentring Leisure (1995), Leisure and Culture (2000), Leisure Theory (2005) e The Labour of Leisure (2010). Especial destaque a sua obra Decentring Leisure (1995), quando este propõe a tese de decentramento, onde estaríamos vivendo uma era pósmoderna de pluralismo radical - onde tudo passa. Segundo Blackshaw (2017a):

[...] enfatizando a importância da alteração social da modernidade para a pósmodernidade, a condição cultural, que ele argumentou, "modificou radicalmente a ideia de lazer". Em um livro, Rojek aparentemente reabilitado a posição de estudos de lazer nas ciências sociais, avançando uma leitura original do lazer e construindo uma nova concepção. Ele tinha transformado o discurso teórico e alterou os limites de estudos de lazer de forma profunda (BLACKSHAW, 2017a, p. 6) ${ }^{1}$.

Todavia, para Blackshaw (2017a), nem os estudos do lazer, nem a abordagem pósmoderna, conseguem explicar adequadamente ao pluralismo encontrado no lazer no

\footnotetext{
${ }^{1}[\ldots]$ stressing the importance of the societal shift from modernity to postmodernity, the cultural condition, which he argued, had 'radically changed the idea of leisure'. In one book, Rojek had seemingly rehabilitated Leisure Studies' position within the social sciences, advancing an original reading of leisure and constructing a new conception. He had transformed the theoretical discourse and changed the boundaries of Leisure Studies in profound ways. BLACKSHAW, 2017a, p. 6) (tradução nossa)
} 
século XXI, pois segundo o autor as falhas de ambas as abordagens têm uma raiz comum ou estão interconectadas. Ambas as abordagens mostram uma marcada relutância em abordar questões fundamentais de lazer: não apenas ao que ele é ou significa, mas como este funciona e representa para os indivíduos, de ver estes como uma prática de vida artística ou mesmo como uma fonte para diferentes tipos de pertença.

Tal fato lança a necessidade de que precisamos desenvolver novas interpretações de lazer, considerando seu pluralismo e o fato de que o que este não é limitado a um modo ou estilo. É por essa razão que Blackshaw (2017a), que os estudos de lazer da forma como conhecíamos está morta. Não o fim do lazer propriamente dito, mas sim o fim das filosofias legislativas em relação a este. O lazer em uma perspectiva funcionalista teria chegado ao fim, não possuindo uma grande narrativa, nem uma história convincente. Para Sloterdijk (2013), o lazer não é um instrumento para legitimar a "reafirmação moral" dos Estudos de Lazer e sim um modo de liberdade humana que não pode ser reduzida à suposições funcionalistas. Blackshaw (2017a), considera que o lazer hoje é difícil de ser definido, podendo ser muitas coisas, ele se torna uma arte de viver, sendo um significado da vida. Podendo ser considerado como um direito de todos, uma vez que não deve ser restrito apenas ao social, cultural ou intelectual, podendo suas interpretações serem compatíveis com todas as possibilidades. Nega-se assim a imposição de qualquer imperativo delimitador ou restritivo de interpretação, não devendo excluir nada em seu processo de análise. Segundo o autor (BLACKSHAW, 2017a), o que se chama de lazer, na verdade é uma forma de vida social, cultural, onde trabalho e lazer muitas vezes se cruzam e se interpenetram mutuamente.

Portanto, a metáfora usada pelo sociólogo polonês, Zygmunt Bauman é extremamente pertinente para compreender o século XXI, ou a passagem de modernidade sólida para modernidade liquida, ou da modernidade e pós-modernidade como preferem 
alguns. Bauman em Modernidade Liquida (2000a), argumenta que as últimas décadas da modernidade passaram por profunda transformação. A modernidade sólida se caracteriza pela solidez das instituições e das relações dos sujeitos. Já a modernidade liquida se caracteriza pela fluidez das relações econômicas, sociais, culturais, permeada por incertezas e inseguranças. O que isso sugere, é que qualquer compreensão do lazer na modernidade líquida deve ser capaz de compreender o significado de incerteza, risco e fragmentação, que são as características dos tempos modernos líquidos. Também, em que se pese, a troca da racionalização pela diferença cultural, pela reflexão individual e o consumismo. Na visão de Bauman, a modernidade líquida é uma sociabilidade que "desvincula" o tempo; enfraquece o impacto restritivo do passado e efetivamente previne a colonização do futuro"(BAUMAN, 1992 p. 190).

Embora muitos autores tenham tentado classificar os sujeitos e entende-los por meio de suas características, demográficas, econômicas, sociais e culturais, buscando identificar padrões e características grupais. Houve uma mudança social de nossa sociedade em que nossas identidades eram amplamente predeterminadas por nossa classe social, gênero, etnia e similares e a arte de viver domina mais do que qualquer outra coisa, e onde nos mesmos sempre permanecem um trabalho em progresso. A classe social, o gênero e a etnia podem ainda exercer algum grau de influência nas nossas formas de lazer, mas certamente não as determinam. De forma semelhante, durante muito tempo os sujeitos mais pobres foram invisibilizados nos estudos do lazer. Se antes do pós-guerra o lazer estava vinculado aos trabalhadores de modo periférico ou inexistente, reconhece que a desigualdade social no lazer é relacional e tem múltiplas dimensões. Todavia nos dias de hoje, mesmo os mais pobres habitam mundos plurais, com diferentes possibilidades para lazer, onde este pode ser o aspecto central de suas vidas. 
Não se quer afirmar aqui nesse estudo, no entanto que a desigualdade social não possui importância para a compreensão do lazer, muito ao contrário. A desigualdade social continua a ter uma influência enorme no lazer das pessoas, a exemplo do tempo e das oportunidades oferecidas a alguns grupos sociais em detrimento de outros. Fato é que a desigualdade nos dias atuais ganha outra dimensão, a pobreza na modernidade sólida é diferente da pobreza na modernidade liquida e onde a contingencia toma o lugar da necessidade. Ao contrário de nossas origens sociais, os desejos dos indivíduos em relação ao futuro podem ser bem mais ousados que nossos antepassados.

A passagem ou mudança de nossa sociedade das últimas décadas do século XX é chamada por Blackshaw como "interregnum", ou seja, uma mudança conjunta que significa o período entre o fim de um tipo de sociedade e o nascimento de outro. Segundo Bauman (2010) apud BLACKSHAW, 2017a, p.37, o termo é definido aqui como o intervalo de tempo que apareceu nas últimas décadas do século $\mathrm{XX}$, quando a modernidade entrou em um enorme estado de fluxo à medida que a antiga "modernidade sólida" baseada no produtor estava morrendo e uma nova a modernidade começa a surgir, o nome que Bauman dá a esse período indefinido de interregnum é a "modernidade líquida".

As pessoas têm seus lugares designados e são inseparáveis das identidades. Tudo está interligado. Você pode conectar uma coisa à outra porque tudo tem seu lugar designado. Nesta distribuição, tudo é "sensivelmente", ou seja, uma coisa ou outra; qualquer compromisso, qualquer indício de contágio, prejudica sua certeza ontológica.

Na modernidade sólida as coisas também foram mantidas separadas em seus lugares apropriados, certas roupas para determinadas ocasiões, público e privado distintamente separados, formal do casual, etc. Havia assim certo temor em misturar as 
coisas, perdem sua ordem e lógica organizacional. Todos se preocupavam com o que estava certo e errado, com as hierarquias, as diferenças classes sociais, entre gêneros, etc.

O senso de classe da modernidade sólida era bastante distinto, pois sua identidade de classe significava quem você era, seu valor, sobre a responsabilidade moral do seu lugar na ordem das coisas. Basicamente, na modernidade sólida sabíamos o que esperar das pessoas e das instituições, seus papéis eram estáveis. Era um mundo consideravelmente previsível, raramente surpreendente e extremamente familiar, onde a perspectiva de que mudasse de forma radical era quase desconsiderada.

As pessoas atuavam de modo quase automático em suas vidas, fazendo o que se esperava delas. Embora não tivessem controle absoluto sobre suas vidas, estavam seguros de que vida seguiria seu curso de forma linear: sairiam da escola, iriam trabalhar, namorar, casar, ter filhos, seriam avós, se aposentariam, sem pensar muito profundamente sobre qualquer coisa. Todavia, com um pequeno empurrão, tudo parecia mudar, e de repente eles tiveram que aprender a acordar e descobrir a si mesmos.

Toda transgressão a ordem estabelecida era punida com a violência tradicional e também com a violência simbólica, que permitia à polícia impor um arbitrário cultural arbitrário - isso fez com que as desigualdades de classe e gênero parecessem naturais e necessárias. A liberdade de "viver fora da lei", parecia uma aventura estranha explorada em filmes e em outros gêneros culturais. As pessoas se comportaram de acordo com os limites e escolhas que encontravam antes deles, um acordo tácito entre as normas e os desvios da norma (FOUCAULT, 1977), esperados pela sociedade.

Todavia, a mudança ou transição de uma modernidade sólida para uma modernidade liquida pressupõe rupturas e descontinuidades no processo histórico, rompesse o suporte de segurança dos indivíduos, por essa razão começam a se questionar 
qual seria o sentido da vida, do trabalho, da família, dos relacionamentos e até mesmo do próprio lazer. Assim, as crenças herdadas perdem sua autoridade.

Ao desafiar este estado de coisas, o ponto de partida de Bauman é que, para entender as mudanças conjunturais instigadas pelo início do interregno, devemos levar em consideração as práticas sociais à medida que emergem contingentemente na vida cotidiana das pessoas. É importante reconhecer duas coisas: desde que as pessoas hoje têm um poder sem precedentes para fazer escolhas individuais e, em segundo lugar, que essas escolhas devem ser entendidas dentro dos habitats em que ocorrem. O que Bauman considera é que tempo e o espaço constituem os habitats onde vivemos nossas vidas e continuamente refazemos nosso senso de nós mesmos.

Viver na modernidade em nossa sociedade como argumenta Heller (1999), é uma sociedade que possui senso de contingência social, ou seja, os indivíduos são desafiados a fazer seu próprio destino individual. Mesmo que classe, o gênero e a cultura podem, em certa medida, ajudar a construir quem somos, os indivíduos modernos não estão restritos a identidades de classe. Os indivíduos acrescentam suas próprias experiências e contribuições para o mundo social (HELLER, 1984, apud BLACKSHAW, 2017a). A contingência permanece assim como um elemento constituinte e inevitável de nossas vidas, onde as escolhas que fazemos, nos separa do que fomos no passado.

Como Bauman diz, nossa liberdade de escolher, nosso próprio destino ou sentido de si é sempre uma relação social, a diferença da ação que depende da vontade dos outros e da ação que depende da vontade própria do indivíduo (BAUMAN, apud BLACKSHAW, 2017a). As influências ocultas ou apenas parcialmente conhecidas da classe social, da comunidade, da família e dos amigos continuam a desempenhar um papel importante para nos tornar o tipo de pessoas que somos, todavia, essas ocupam papel secundário.

licere, Belo Horizonte, v.23, n.3, set/2020. 
A metáfora da liquidez, ou do lazer liquido, é como resultado, uma questão de pensamento dialético e não o desenvolvimento da teoria. A justaposição de "solidez e" liquidez "oferece uma nova maneira de pensar sobre o lazer. Esta é uma maneira de pensar que não depende da teoria, mas sim da metáfora, que é a ferramenta retórica que nos permite "desfamiliarizar o familiar" e mostrá-lo em uma nova luz (BAUMAN, 1990). A metáfora é essa parte do idioma que nos permite praticar a hermenêutica. Isto é, por um lado, fazer sentido (ou seja, tornar inteligível o que não poderia ser entendido) e, por outro, aprofundar a nossa compreensão, de modo a tornar o significado ainda mais significativo, no processo de criação de alguns princípios de funcionamento democráticos à medida que avançamos.

A modernidade liquida, portanto, considera importante em suas acepções a conjugação da imaginação como nas observações do mundo empírico, seria não só um registro de fatos observáveis, mas também uma leitura mais profunda delas com a ajuda da imaginação. O pensar líquido move-se constantemente entre a crítica ética e a contemplação estética e reconhece que o objetivo não é a busca ou a invenção, mas reunirse em assembleia. Esta metáfora inventada por Deleuze e Guattari ajuda a compreensão do pensamento liquido do lazer, pois permite ir além da distinção entre conhecimento e imaginação, uma forma mais humilde e híbrida que tem um status completamente diferente, é dois planos de assunto e expressão, uma colcha de retalhos de conteúdo heterogêneo, fluido (DELEUZE E GUATTARI, 1987, apud BLACKSHAW, 2017a, p. $58)$.

Blackshaw (2017a), insere ainda na discussão do lazer a tese de desencantamento do mundo, a partir da ótica de Max Weber na sua obra "The Protestant Ethic and the Spirit of Capitalism", escrita em 1904. Weber argumentou que o surgimento do capitalismo moderno é acompanhado por um processo inexorável de racionalização que 
por sua vez desencadeia o "desencanto do mundo", que pode ser explicado como a perda do mito, o fim da filosofia, a perda de beleza, abandono do fanatismo, loucura e legitimação por meio do carisma. Dito de outra forma, significa que as esferas dominantes da vida moderna não proporcionam vida com significado, ou seja, um desencantamento.

Dessa forma o processo de racionalização moderno não apenas destrói o mundo do universo invisível dos espíritos e divindades que até então habitaram o mundo natural e deu significado à vida humana, substituindo o mágico e o místico por alternativas abertas aos cálculos da razão técnica, mas também surge a tendência de ver o mundo em termos mecanicistas. Altera-se, portanto, os valores tradicionais por racionalização puramente instrumental; o surgimento de uma atitude de realização mundana impessoal, fundamentada na ética puritana da vocação; a crescente importância do conhecimento especializado estreito em economia e administração e o desenvolvimento concomitante da burocracia. O resultado disso é que a substituição do capitalismo pela fé religiosa substituindo o controle místico por meios tecnicamente racionais.

Blackshaw (2017a), inicia sua argumentação afirmando que:

[...] as pessoas sempre foram atraídas pelo encantamento e que o "interregnum" entre a modernidade sólida para a modernidade liquida, trouxe consigo ofereceu novas formas de encantamento (BAUMAN, 1992), ou que Heller (1999) chama de "iluminação romântica" uma vez que o mundo finalmente se transformou em uma pluralidade de mundos (BLACKSHAW, 2017, p. 68).

Assim como Weber outros autores consideram que o "desencamento do mundo", surgiu com o consumismo e que isso teria séria implicações nas diversas esferas da sociedade, não apenas para o lazer, mas para a liberdade humana de forma mais geral. Há uma extensão da produção bibliográfica ao longo da história de críticos em relação ao capitalismo e sobretudo do impacto que o consumo crescente representa para a liberdade humana.

licere, Belo Horizonte, v.23, n.3, set/2020. 
De forma semelhante, Bauman (2008) faz sua crítica ao consumismo, onde na modernidade líquida, o "modo de vida mediado pelo mercado", penetram no indivíduo mecanismos, normas e valores de mercado em todos os aspectos da existência humana subtraindo do indivíduo autonomia, a autenticidade e outros tipos de atividade de representação do significado, até mesmo a ideologia, como principal defensor da identidade e da diferença social. Esse sentimento de desorientação é chamado por Bauman (1998) de "Deriva".

Os indivíduos subjugados em uma modernidade sólida, são naturalmente atraídos pela ideia de liberdade da modernidade liquida, muito embora em alguns casos seja simplesmente uma liberdade de consumo, ensejando assim outro tipo de subjugação, só que desta vez de forma mais sutil através da sedução e não da repressão (BAUMAN, 1992 apud BLACKSHAW, 2017a, p. 66).

Em duas das obras de Blackshaw (2010; 2013), este considera que o mercado e o consumismo se apresentam como desafios mais insidiosos e entrincheirados para a liberdade humana nos dias de hoje. Claramente, essa visão simplifica grosseiramente alguns problemas complexos. A busca performativa do "autoconhecimento" e a distinção entre lazer autêntico e lazer consumista (ou qualquer outra dicotomia) perde seu significado e o mundo é aberto a novas possibilidades de encantamento.

Muito embora Bauman (1990) reconheça que esse modo de vida mediado pelo mercado a maioria das atividades humanas é comercializada, privatizada e individualizada e pode de alguma forma arrefecer o papel da imaginação. Adverte ainda o autor que o pior não é o gosto pelas compras que nos atrai, esse não seria o cerne do problema, mas sim os altos e baixos da própria vida, as frustrações e desapontamentos, de sonhos satisfeitos e sucessos parciais. Para usar a própria analogia de "caçador" de Bauman, ser realmente livre é perseguir a lebre, não apenas para pegar. Apanhar a lebre 
prenuncia o fim de todas as expectativas, salvo se outra caçada for planejada e imediatamente empreendida. Em uma sociedade de caçadores, uma perspectiva de fim da caça não é tentadora, mas ao mesmo tempo assustadora - uma vez que significa uma derrota pessoal.

Se não considerarmos, portanto, o modo de vida mediado pelo mercado e nossos próprios anseios, podemos perder de vista a ambivalência da liberdade. A atitude hoje de nossa sociedade se resume, portanto, naqueles que gostam de "ter" e aqueles que buscam o "ser".

Na opinião de Bauman, a modernidade líquida surge em um momento em que a uma parcela de pessoas poderia dar ao luxo de consumir itens que não eram necessários para a mera sobrevivência. $\mathrm{O}$ consumismo pressupõe a aproximação entre o consumidor e a mercadoria, mediado pelo transporte, assim a modernidade liquida é um mundo no qual o fluxo e o movimento são uma obrigação. Nós somos obrigados a agir, em um mundo que está sempre em movimento e onde nada permanece o mesmo durante muito tempo. Talvez por isso nessa incerteza a religação seja uma opção para os mais inseguros.

A modernidade líquida é episódica e contingente e a incompletude essencial da vida não apenas nos convida a criar demandas e seguir as instruções de uma educação voltada para o consumidor ao longo da vida (BAUMAN, 2004, apud BLACKSHAW, 2017a, p. 77), que nos diz como viver, que música ouvir, onde comprar, o que comer e beber e aonde ir para as nossas férias. Blackshaw (2017a) sugere, portanto que consumir a vida faz todo o sentido, já que é através do consumo que percebemos somos capazes de exercer nossa individualidade.

A realização do distúrbio descentrado que sustenta a modernidade líquida foi sua capacidade de chamar a atenção do homo faber e homo ludens para a vida do homo consome (BAUMAN, 2004). Na verdade, como Bauman argumenta, é a instantaneidade 
de cultura de consumo e sua capacidade de se entregar a esperanças e sonhos de um consumidor. A compreensão de Bauman sobre o consumismo sugere a maneira como Hannah Arendt entendeu o totalitarismo. Seus membros não têm interesses, não se preocupam com seu "bem-estar", sem crenças coletivas, comunidade ou identidade que eles podem chamar de seus. O que eles têm é uma ansiedade provocada pela solidão, ou o que Arendt (1972, p. 477) chamou de "a experiência de não pertencer ao mundo", e um desejo de mergulhar no consumismo, mesmo que isso signifique, em última instância, extinguir sua "identidade individual permanentemente". O que o consumismo oferece é um efêmero sentimento de pertença.

Bauman demonstra que a emoção de consumir é a ambivalência que representa na rede móvel entre liberdade e segurança. Em poucas palavras, não só os desejos de desejos dos consumidores nunca podemos satisfazer adequadamente, exceto apenas temporariamente, mas o ato de consumir é mais emocionante do que realmente adquirir bens de consumo. $\mathrm{O}$ verdadeiro prazer de fazer compras reside na emoção da busca em vez da aquisição de produtos. Bauman sugere que consumir pode ter uma ampla gama de significados e vir com uma ampla gama de práticas, mas o fato é que não é realmente o consumismo per se que nos interessa. Em outras palavras, os significados e sim as práticas que vêm com o consumo não são tem o objetivo de satisfazer as necessidades dos consumidores. O deleite das férias é substituído pelo deleite das compras, que nos bombardeiam a todo momento com propagandas de todo tipo de produtos, alguns dos quais podemos e outros não podemos pagar. Como indivíduos racionais, sabemos que nossa sobrevivência econômica depende de comprar apenas o que podemos pagar, mas a disponibilidade de crédito nos encoraja a ir além de nossos meios. A modernidade líquida é, de fato, uma sociedade em que essas virtudes ligadas à cidadania foram subsumidas pelo papel de consumidor, onde sua posição moral depende de sua capacidade de pagar 
as contas. Como Bauman (2004b, p. 74) diz, é como se "nós fomos treinados para deixar de nos preocupar com coisas que ficam teimosamente além do nosso poder, como questões mais importantes da coletividade em uma sociedade e concentramos nossa atenção e energia nas tarefas dentro do alcance (de competência) individual, da competência e da capacidade de consumo".

Segundo Blackshaw (2017a) a modernidade líquida redefina os limites entre as divisões de classe social entre aqueles que consomem efetivamente e aqueles que não conseguem consumir, apesar dos seus desejos. Essa sociedade fragmentada é impulsionada pelo "princípio do prazer". Assim, Bauman aventura-se a dizer que se na modernidade sólida era uma sociedade de classes baseada na vigilância panóptica, na modernidade liquida é o consumismo com a sua (des) organização do controle social baseada na "precarização", como o "princípio da realidade" e o "princípio do prazer" que o caracterizam.

O verdadeiro poder que advém dessa modernidade liquida seria não a ideologia e som o poder da sedução, que ajuda a compreender o controle social. Existiria, portanto, por parte dos indivíduos um desejo de ser seduzido, algo para acreditar e de se sentir pertencente. Na verdade, esse sentimento é fé e crença, indiferente em que relação se estabeleça, ou seja, fé na roupa que compramos, fé em nós mesmos, fé em nossos relacionamentos, fé no mercado, fé na religião e até mesmo fé na raiva. Todavia Bauman alerta que a fé é algo extremamente frágil, passível de quebrar caso percamos o interesse.

Bauman sugere que nos afastemos da linguagem reutilizável dominante do consumismo para um discurso alternativo, ou seja, ao invés de consumir avidamente, deveríamos prestar atenção aos pequenos e verdadeiros detalhes da vida. Ao afastar essa ideia de consumidor de vidas desordenadas em busca de um novo relacionamento com o mundo, que é ao mesmo tempo mais completo e mais responsável. Blackshaw (2017a), 
defende a ideia de que os estudos de lazer não prestam atenção suficiente a imaginação humana, uma nova forma de ver e sentir o lazer. Para ele, o lazer pode ser visto como uma espécie de prática espiritual ou uma fonte de encantamento, o que lhes permite tornar suas vidas significativas, além de colocá-las no caminho da autenticidade. O problema é que para Bauman, precisamos nos desprender da "atitude do consumidor", muito embora isso seja impossível, dada onipresença da modernidade liquida que influenciam as ações dos sujeitos. Tal como Max Weber, Bauman buscando evidenciar a perda de encantamento para mudanças religiosas e econômicas que inauguraram o capitalismo produtor moderno para os efeitos putativos de uma sociedade pós-produtiva baseada no consumismo, deixando-nos com pouca experiência.

Para Bauman o nosso lazer de hoje é explicitamente orientado para o consumidor. Mas o lazer moderno sempre foi um ato de equilíbrio da produção artística e de consumismo. Na modernidade líquida, a distinção entre lazer autêntico e lazer consumista perde o seu significado. Existe apenas um lazer mais ou menos capaz e digno de propagação: "lazer devocional" e "lazer performativo". A falsa dicotomia de "produtores" e "consumidores" é substituída pela distinção entre o comprometido e o não comprometido: por um lado, aqueles que tornaram suas vidas significativas e, por outro lado, aqueles que preferem tomar a vida à medida que ela vem, ou - alternativamente quem apenas quer esquecer a inexistência existencial da vida.

Um dos objetivos centrais de Blackshaw (2017a) é explorar de maneira critica, o lazer daquelas pessoas que decidem fazer do seu tempo livre um dos aspectos centrais da sua vida, de tonar sua vida mais significativa através do lazer através do "lazer devocional", ou ainda daqueles que vem o lazer de maneira "performativa”. Ele alega que muitos de nós procuram fugir das opções disponíveis do mundo do consumidor. O encantamento mesmo num momento de liquidez não tornou o "encantamento" obsoleto, 
e o aproximou da esfera do lazer. Seria através do lazer devocional e performativo que as pessoas se comprometem na criação de novos modos de vida, habitats, esferas, formas, redes, espaçamentos e outros tipos de arranjos sociais, que por sua vez estão pautados na liberdade. A busca do lazer numa perspectiva que foge do ordinário tem como objetivo a busca do encantamento e da busca do significado.

A maneira como o lazer se efetiva no século XXI, desempenha um papel fundamental na construção deste novo temperamento; é através de "lazer devocional" e "lazer performativo" que nos comprometemos a criar novos mundos da vida - habitats, esferas, formas, redes, espaçamentos e outros tipos de arranjos sociais - por causa da nossa liberdade.

O "lazer devocional" e o "lazer performativo" para Blackshaw (2010), apresenta novos tipos de encantamento e auto-realização na modernidade liquida para aqueles que ele chama de artistas da vida. O lazer tem um objetivo que seria permitir que façamos coisas que não conseguimos fazer antes, em práticas extraordinárias. Por meio dessas novas formas de lazer constantemente reinventamos a vida para experimentar novas formas de ser no mundo, o que por sua vez gera novas formas de interação comunitária. Em cada momento histórico temos diferentes formas de nos expressar, inclusive no lazer e também por meio do corpo. O corpo social restringe a forma como o corpo físico é percebido.

Blackshaw reitera que muitos são os artistas da vida, como o fazendeiro que possuía certa liberdade em seu trabalho e na atividade criativa. Os turistas podem ser vistos como artistas, ou como coloca Bauman, como "os mestres supremos da arte de derreter os sólidos e despreocupados os fixos" (BAUMAN, 1997, apud BLACKSHAW, 2017a , p. 98). Os turistas, segundo ele, estão encantados com as possibilidades de escolha de suas viagens, de pensamento e da própria viagem. Os turistas estão encantados com as 
possibilidades que o próprio pensamento de viagem lhes apresenta e sempre embarcam em suas viagens por escolha. Na modernidade líquida, não existe um "corpo social" que permita colocar limites sobre onde minha imaginação pode me levar e com isso meu direito de desocupar a identidade social que atualmente ocupo. É postulado que a "vida" e o "lazer" uma relação mais consistente quando comparado a vida e trabalho. Nessa última relação, o lazer é visto muitas vezes como uma vida de fuga e não como uma transcendência. Assim, como os indivíduos gastam seu tempo livre - o que eles podem e o que eles escolhem fazer é uma das características de suma importância em relação ao lazer.

Para muitos indivíduos hoje, a "vida" é invariavelmente moldada pelo "lazer"; ou seja, eles conseguem estabelecer uma relação mais fácil entre o um e o outro. Para emprestar uma visão de Heller (2011), alguns indivíduos descobrem em seu lazer que o mundo tem um centro e isso assume a forma de uma vocação, ao qual eles estão profundamente comprometidos, e eles vivem suas vidas tentando descobrir seu segredo. Aqui a escolha traduz a liberdade em necessidade. Escolher este modo de vida é que ambos se sintam inconscientemente em casa em um mundo de vida de lazer e que conseguem se tornar alguém no mundo, ou seja, alguém distinto.

A afirmação de Max Weber de que o indivíduo é a única realidade discernível e que qualquer análise deve começar com as ações dos indivíduos. Os membros da sociedade fundadora como indivíduos é a marca registrada da modernidade (BAUMAN, 1999 apud BLACKSHAW, 2017). Com base no trabalho de Bauman, argumenta-se que a individualização é o destino de todos os indivíduos hoje. Em outras palavras, no século XXI, a liberdade baseia-se no modelo clássico de auto-escolha: "gnothi seauton", a antiga injunção grega inscrita em letras douradas sobre o pórtico do templo em Delphi, o que significa "conhecer a você mesmo". Este modo de vida trazido ao ser universal pela 
modernidade e transformado de um "dado" para uma "tarefa" (BAUMAN, 2000 apud BLACKSHAW, 2017a, p. 101) como um destino pessoal no interregno não é, como Agnes Heller argumenta, "um produto de mera introspecção, mas o resultado da ação; isto é uma "prova" ou um "tornar-se" pelo qual o Eu alcança o tipo de ações apropriadas para o caráter e o destino escolhidos por si mesmo. Uma vida inicial de "tornar-se" não admite identidades fixas; o que isso sugere é que deve ser entendido como irredutivelmente mutável e heterogêneo. Isto é, antes e mais, porque a pré-condição do indivíduo moderno de fato é o potencial para viver uma vida ainda não determinada.

Argumenta-se que os indivíduos saboreiam perder-se no seu lazer porque é aqui que eles esperam conhecer a si próprios. O lazer, é o meio pelo qual eles podem descobrir como controlar e ordenar suas vidas. Quando esse controle e ordem são estabelecidos, o lazer desaparece e se torna a arte de viver.

\section{Considerações Finais}

Considerada a premissa da modernidade liquida, concluímos que tudo em nossa sociedade está em permanente mudança, desconhecido, reflexo de um universo de possibilidades onde o lazer e a própria ideia de lazer deve ser repensada. Considerar o lazer para além de suas dicotomias tradicionais nos faz pensar sobre as novas formas de pensar, pesquisar outras formas de lazer possíveis. Vale destacar que pata além do que convencionalmente é considerado como lazer normal, a outras formas de lazer, ou o chamado "Abnormal leisure" ou "Dark Leisure", ou seja, o lazer anormal ou lazer obscuro, pode envolver violência, prazer, sexo, prostituição, uso de drogas, envolver dor, tortura, morte, medo, shows, etc. Existe um grande número de pesquisadores ${ }^{2}$ que se debruçam, sob essas temáticas trabalhando esse tipo de lazer.

\footnotetext{
${ }^{2}$ CARR e PORIA, 2010; STENSENG; RISE e KRAFT, 2011; STONE e SHARPLEY, 2013; ROJEK, 1999; WILLIAMS, 2009
}

licere, Belo Horizonte, v.23, n.3, set/2020. 
Grande parte dos sujeitos em nossa sociedade estão em busca de sua identidade, de suas paixões e de seus propósitos, levando eles a buscar no lazer uma forma de devoção (não no sentido sacro), mas sim no sentido em que os sujeitos são atores protagonistas dessa arte de viver. Estamos em busca de uma identidade e de práticas de lazer que são fluídicas. Embora, classe social, o gênero e a etnia possam contribuir de alguma forma na compreensão de sua influência sobre o lazer, mas não são determinantes. De forma semelhante não se pode esquecer das desigualdades sociais, que acabam também por influenciar assim como outras variáveis, a prática do lazer. Diante da insuficiência dos paradigmas tradicionais que buscam explicar o lazer pela via dicotômica entre lazer e trabalho, produtores e consumidores, autêntico e inautêntico, emerge a necessidade de uma nova perspectiva ou paradigma de análise do lazer. Portanto a ideia de Blackshaw (2017) é buscar compreender o que fazem os sujeitos com o tempo livre, fazendo deste, muitas vezes aspectos centrais de sua existência, ao que ele designa de lazer devocional ou lazer performativo. É por meio dessas novas formas de lazer que seria possível reinventar a vida e de novas formas para experimentar novas formas de ser no mundo. Com essa liberdade de ação em relação ao lazer seriamos, portanto, artistas de nossas próprias existências, dando novo significados a ela e gerando novas formas de interação comunitária. Poderíamos, portanto, nos questionar se seria possível a existência do lazer para aqueles que estão encarcerados, mesmo estando privados de sua liberdade? Seria possível possuir lazer sem ter trabalho ou capital? Poderíamos considerar que atividades antes consideradas obrigações sociais (como a família, a religião, participação cívica e o próprio trabalho e estudos, entre outras) possam ser lazer? Ou no mínimo conter em si, ainda que temporariamente momentos de lazer? Em que medida ou de que forma o lazer hoje pode contribuir para a compreensão das identidades de sujeitos de uma sociedade liquida cada dia mais 
difusas?

\section{REFERÊNCIAS}

ARENDT, H. Entre o passado e o futuro. São Paulo: Perspectiva, 1972

BAUMAN, Z. Modernidade líquida. Rio de Janeiro: Jorge Zahar Ed., 2001.

Retropia. Rio de janeiro: Jorge Zahar Ed., 2017.

O mal-estar da pós-modernidade.Rio de Janeiro, Jorge Zahar Ed. 1998.

'Liquid Sociality'. In: GANE, N. The future of social theory. London: Continuum.2004.

Vida para consumo: a transformação das pessoas em mercadoria. Rio de Janeiro: Zahar Ed., 2008.

BLACKSHAW, T. Re-Imagining Leisure Studies. Routledge Critical Leisure Studies. London and New York: Routledge, 2017a.

Zygmunt Bauman. Routledge. 2005a.

BLACKSHAW, T. Emancipation: fractured lives, certain leisure? In: ROJEK, C. (Ed.) Leisure Studies, v. 4. Key Issues for the 21st Century. Sage, pgs. 311-329, $2010 \mathrm{~b}$.

(Ed.). Routledge handbook of leisure studies. Routledge, 2013.

CARR, N.; PORIA, Y. (Ed.). Sex and the sexual during people's leisure and tourism experiences. Cambridge Scholars Publishing, 2010.

CLARKE, J.; CRITCHER, C. The Devil Makes Work. London: Macmillan, 1985

DELEUZE, G., GUATTARI, F. A thousand plateaus: Capitalism and schizophrenia. Bloomsbury Publishing, 1988.

FERREIRA, C. L. Trabalho, Tempo Livre e Lazer: uma reflexão sobre o uso do tempo da população brasileira. 2010. Dissertação (Mestrado em Engenharia da Produção). Universidade Tecnológica Federal do Paraná Programa de Pós-Graduação em Engenharia de Produção, Ponta Grossa, PR, 2010.

FOUCAULT, M. Vigiar e punir: nascimento da prisão. 35. ed. Petrópolis: Vozes, 1977.

HELLER, A. A Theory of Modernity. Oxford: Blackwel, 1999.

Self-representation and the representation of the other. In: HELLER, A.;

RUNDELL, J. L. Aesthetics and Modernity Essay. Agnes: Rowman and Littlefield, 2011

ROBERTS, K. Contemporary Society and the Growth of Leisure. London: Longman,

licere, Belo Horizonte, v.23, n.3, set/2020. 
1978.

ROBERTS, K. Leisure. 2. ed. London: Longman, 1981.

Youth and Leisure. London: Allen \& Unwin, 1983.

ROJEK, C. Capitalism and Leisure Theory. London: Tavistock, 1985.

. Baudrillard and Leisure, Leisure Studies, v. 9, n.1, p. 7-20, 1990.

Decentring Leisure: Rethinking Leisure Theory. London: Sage, 1995.

. Deviant leisure: The dark side of free-time activity. Leisure studies: Prospects for the twenty-first century, p. 81-96, 1999.

Leisure and Culture. Basingstoke: Macmillan, 2000.

. The Consumerist Syndrome in Contemporary Society: An Interview with Zygmunt Bauman, Journal of Consumer Culture, v.4, n. 3, p. 291-312, 2004.

2005.

Leisure Theory: Principles and Practice. Basingstoke: Palgrave Macmillan,

The Labour of Leisure: The Culture of Free Time. London: Sage, 2010.

SLOTERDIJK, P. In the World Interior of Capital: Towards a Pholosophical Theory of Globalization. Cambridge: Polity Press, 2013.

STENSENG, F.; RISE, J.; KRAFT, P. The dark side of leisure: Obsessive passion and its covariates and outcomes. Leisure Studies, v. 30, n. 1, p. 49-62, 2011.

STONE, P. R.; SHARPLEY, R. Deviance, dark tourism and 'dark leisure': Towards a (re) configuration of morality and the taboo in secular society. Contemporary perspectives in leisure: Meanings, motives and lifelong learning, p. 54-64, 2013.

WILLIAMS, D. J. Deviant leisure: Rethinking "the good, the bad, and the ugly". Leisure sciences, v. 31, n. 2, p. 207-213, 2009.

\section{Endereço do Autor:}

Luiz Fernando Roscoche

Alameda Leandro Ribeiro, S/N - Aldeia

Bragança - PA - 68.600-000.

Endereço Eletrônico: luizfrrs @ hotmail.com 